\title{
Transfusion-Related Acute Lung Injury
}

\author{
Hava Üsküdar Teke • Orhan Behret • \\ Deniz Teke
}

Received: 20 February 2012/Accepted: 31 August 2012/Published online: 18 September 2012

(C) Indian Society of Haematology \& Transfusion Medicine 2012

\begin{abstract}
Transfusion-related acute lung injury (TRALI) is related to the transfusion of blood components. Typically, it is a clinical syndrome, characterized by the sudden onset of dyspnea, hypoxemia and bilateral non-cardiogenic pulmonary edema. A 83-year-old female patient with a history of AML developed TRALI after receiving 6 units of platelets. TRALI symptoms was started 10 min later the transfusion. AML is a risky group for TRALI. While giving transfusion to the risky groups of TRALI one must be more careful. The mortality rate caused by TRALI will decrease if the patient who is thought to have TRALI or who has bilateral pulmonary edema without any other reason showing the existance of TRALI is given ventilatory support at the right time.
\end{abstract}

Keywords TRALI Syndrome $\cdot$ Ventilator

\section{Introduction}

Transfusion-related acute lung injury (TRALI) is related to the transfusion of blood components. Typically, it is a clinical syndrome, characterized by the sudden onset of dyspnea, hypoxemia and bilateral non-cardiogenic pulmonary edema [1]. TRALI, is the most common reason of deaths that is related to transfusion. However, incidence of deaths is not known exactly [2]. The TRALI incidence is $1 / 2,000-1 / 5,000$ for all blood components and 1/432 for platelets and occurs within $6 \mathrm{~h}$ of transfusion [1,3]. Plasma

H. Ü. Teke $(\bowtie) \cdot$ O. Behret · D. Teke

Department of Hematology, Anesthesiology, Cardiology,

Kayseri Education and Research Hospital, Kocasinan, Kayseri, Turkey

e-mail: havaus@yahoo.com and platelets are the most common blood products which cause TRALI [2].

\section{Case}

An 83-year-old female patient. In the patient's laboratory tests, who was admitted to hematology polyclinic with fatigue and ecchymose complaints, thrombocytopenia and neutropenia were found out. After the observation of peripheral blood smear; since, blast and dysplastic neutrophils were observed; bone marrow aspiration, biopsy and flowcytometric tests were held considering the existence of myelodysplastic syndrome or acute leukemia. After the test results, the patient was diagnosed by acute myeloid leukemia. Because the patient was too old and did not accept to use chemotherapy, the patient was observed with supportive treatment. The patient was given platelet concentrate or platelet concentrate by apheresis when her platelet counts were under $10 \times 10^{3} / \mathrm{UL}$. When the patient's hemoglobin count was under $8 \mathrm{~g} / \mathrm{dL}$ she was given erythrocyte concentrate. The patient who had headache during the observation in January 2012 and whose thrombocyte level was under $5 \times 10^{3} / \mathrm{UL}$, had a cerebral CT scan and bleeding was not observed. The patient was given 6 units platelet concentrate which was randomly pooled, irradiated and depleted leukocytes. The patient, who had sudden onset of dyspnea $10 \mathrm{~min}$ after the transfusion, was thought to have TRALI. Auscultation of lung fields which was carried out early during the complaints was normal. Pulse oximetry showed that $\mathrm{O}_{2}$ saturation was $60 \%$. Her blood pressure was $140 / 100 \mathrm{mmHg}$, pulsation was $110 / \mathrm{min}$. The patient was given $\mathrm{O}_{2}$ via the oxygen mask and was injected antipyretics, corticosteroids, diphenhydramine and IV diuretics. The breathing problem of the patient increased within $10 \mathrm{~min}$. 


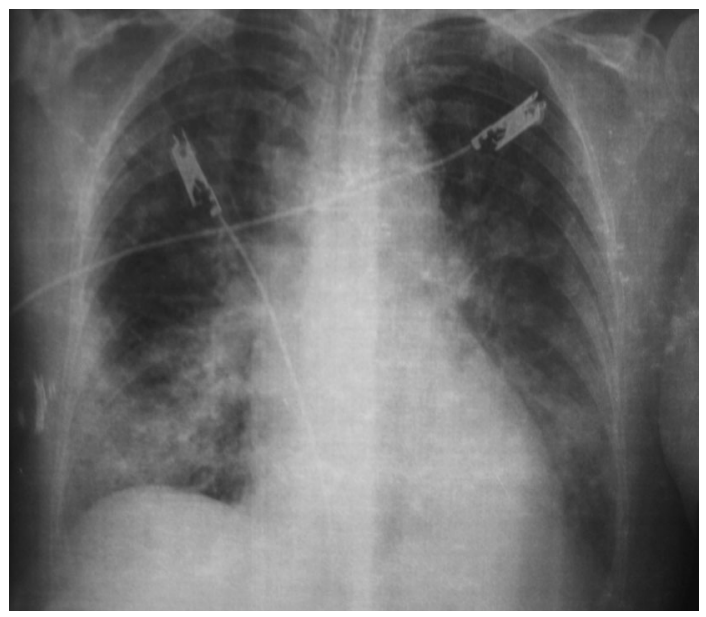

Fig. 1 Bilateral pulmonary infiltration

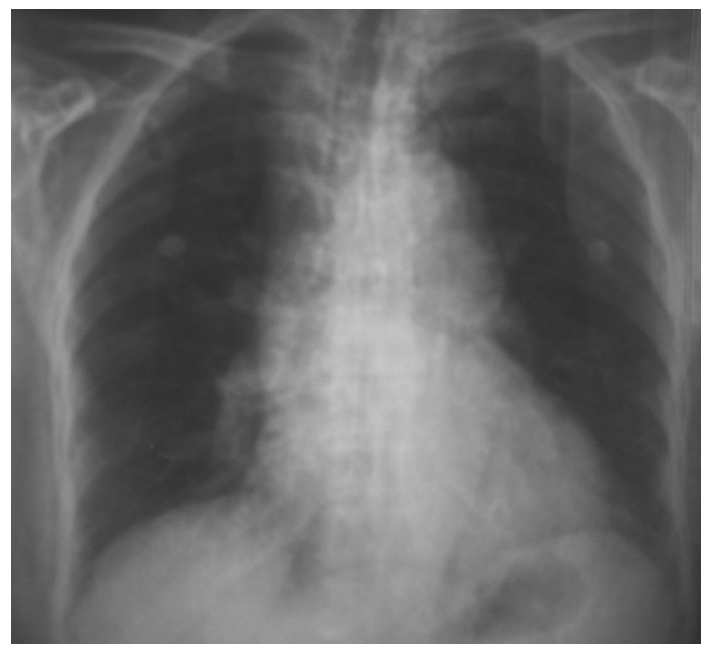

Fig. $2 \mathrm{X}$-ray, after the ventilatory support treatment

Pulse oximetry showed that $\mathrm{O}_{2}$ saturation decreased as $40 \%$ even during the $\mathrm{O}_{2}$ treatment. When the patient's, who developed cyanosis, lung was examined; crepitant rale was diagnosed around bilateral upper zones. Afterwards, the patient was intubated and was given ventilatory support.
$\mathrm{X}$-ray results showed the existence bilateral pulmonary edema (Fig. 1). ECG results showed nothing other than sinus tachycardia. Echocardiography results showed that systolic functions were normal. $\mathrm{pH} 7.08, \mathrm{pO}_{2} 114.5 \mathrm{mmHg}$, $\mathrm{pCO}_{2} 50.8 \mathrm{mmHg}, \mathrm{HCO}_{3} 14.3 \mathrm{mmol} / \mathrm{L}$ were found in arterial blood gas which was taken just after the patient was given mechanical ventilation. The patient, who was observed for $18 \mathrm{~h}$ via mechanical ventilation, was given $\mathrm{NaHCO}_{3}$ infusion, IV diuretics, corticosteroid and eptantoin (because of convulsion). It was observed that pulmonary edema decreased within hours when the patient was supported by mechanical ventilation (Fig. 2). The patient, who was observed for nearly $18 \mathrm{~h}$ via mechanical ventilation, was extubated at the 18th $\mathrm{h}$. The laboratory results are shown with the following Table 1 .

\section{Discussion}

TRALI, can be defined as the onset of dyspnea which is related to the transfusion of blood products, usually occurring in the first $30 \mathrm{~min}$ of transfusion and non-cardiogenic pulmonary edema which is not caused by any other reason [1]. Patients with emergency cardiac surgery, hematologic malignancy, massive transfusion, sepsis, mechanical ventilation, multiparous female donors, human leukocyte antigen (HLA) class I and II antibodies in the platelet donor's plasma and plasma-rich components, are at the risk for development of TRALI [4,5]. There is also a relationship between platelet age and TRALI. Antileukocyte antibodies, activation of the compleman cascade, neutrophil (PMN)-mediated lung injury and pulmonary leukostasis are responsible for the pathogenesis of TRALI [6-8]. Furthermore, IL-6 and IL-8 are essential cytokines which stimulate PMN and play important role in pathogenesis of TRALI $[9,10]$. As the platelet age increases, the level of IL- 6 and IL- 8 increase in the platelet concentrates. The infusion of these platelet concentrates increase the risk of TRALI [1, 11]. Being an AML patient she had hematologic disease therefore, she was among the risky group for TRALI. Moreover, since the

Table 1 The laboratory levels before TRALI and during the ventilation

\begin{tabular}{llllllll}
\hline & Pre-transfusion & $\begin{array}{l}\text { After } 10 \mathrm{~min} \\
\text { of transfusion }\end{array}$ & $\begin{array}{l}\text { Start of } \\
\text { Mechanical } \\
\text { Ventilation }\end{array}$ & $\begin{array}{l}\text { Sixth hour of } \\
\text { mechanical } \\
\text { ventilation }\end{array}$ & $\begin{array}{l}\text { Twelfth hour } \\
\text { of mechanical } \\
\text { ventilation }\end{array}$ & $\begin{array}{l}\text { Eighteenth hour } \\
\text { of mechanical } \\
\text { ventilation }\end{array}$ & $\begin{array}{l}\text { After } 1 \mathrm{~h} \text { of } \\
\text { extubation }\end{array}$ \\
\hline $\mathrm{stO}_{2}(\%)$ & - & 60 & 92 & 97 & 99 & 90 & 88 \\
$\mathrm{HR}($ minute) & 76 & 110 & 109 & 89 & 87 & 95 & 109 \\
$\mathrm{BP}(\mathrm{mmHg})$ & $100 / 60$ & $140 / 100$ & $130 / 60$ & $124 / 65$ & $146 / 74$ & $162 / 109$ & $161 / 84$ \\
$\mathrm{pH}(\mathrm{mmHg})$ & - & - & 7.068 & 7.320 & 7.431 & 7.464 & 7.480 \\
$\mathrm{pO}_{2}(\mathrm{mmHg})$ & - & - & 114.5 & 111.1 & 110 & 59.4 & 35.9 \\
$\mathrm{pCO}_{2}(\mathrm{mmHg})$ & - & - & 50.8 & 46.9 & 50.4 & 45 \\
\hline
\end{tabular}


platelet concentrates that we used were for 5 days and included older thrombocyte, the patient was among the she was in high risk group for TRALI.

To diagnose TRALI; dyspnea with acute onset caused by acute lung injury, hypoxemia and bilateral infiltrates on frontal chest radiograph should be observed together with the absence of the evidence of left atrial hypertension and another reason to cause acute lung injury during or within $6 \mathrm{~h}$ of transfusion [5]. Since the echocardiography of the patient was normal, there was bilateral infiltrate on chest radiograph, which was observed within $10 \mathrm{~min}$ after the pooled platelet concentrate together with the acute onset dyspnea and hypoxemia and there was not other reason for ALI, the existence of TRALI was found out. Signs and symptoms include tachypnea, pulmonary secretions, hypotension (less commonly hypertension), fever, tachycardia and cyanosis. Auscultation of the lung fields reveals diffuse rales [5]. The patient had tachypnea, pulmonary secretion, tachycardia and cyanosis. However, the patient had hypertension which was not common. Although, auscultation of the lung fields was normal during the onset of dyspnea, diffuse rales were found out within $10 \mathrm{~min}$. Laboratory tests which strongly support, but are not required for the clinical diagnosis of TRALI, include the demonstration of HLA class I or class II or neutrophilspecific antibodies in donor plasma. Because the patient was found to have TRALI as clinically, no other laboratory tests were required.

In most cases, mechanical ventilation and $\mathrm{O}_{2}$ support are required for the treatment of TRALI. Different from acute respiratory distress syndrome which are caused by other reasons, patients with TRALI recover quickly with resolution of pulmonary infiltrates within $96 \mathrm{~h}$ of the transfusion. The mortality rate ranges from 5 to $10 \%[6,12]$. It was observed that pulmonary infiltration disappeared just after the $18 \mathrm{~h}$ of ventilatory support and transfusion, and full recovery was observed after the patient was extubated. As soon as the TRALI is diagnosed, the necessity of ventilatory support should be checked. As in our case, if the patient is given ventilatory support without wasting much time, the mortality rate caused by TRALI will decrease.

As a result, in case of sudden onset of dyspnea, tachypnea and hypoxemia which developed within the first $6 \mathrm{~h}$ after the transfusion, the first thing to consider is TRALI and it should be evaluated whether the patient needs ventilatory support or not. While giving transfusion to the risky groups of TRALI, one must be very careful. The mortality rate caused by TRALI will decrease, if the patient who is thought to have TRALI or who has bilateral pulmonary edema without any other reason showing the existance of TRALI is given ventilatory support at the right time.

\section{References}

1. Siliman C, Boshkov L, Mehdizadehkashi Z, Elzi D, Dickey W, Podlosky L, Clarke G, Ambruso D (2003) Transfusion-related acute lung injury: epidmiology and a prostpective analysis of etiologic factors. Blood 101:454-462

2. Sokolovic M, Pastores SM (2010) Transfusion therapy and acute lung injury. Expert Rev Respir Med 4:387-393

3. Goldman M, Weberet KE, Arnold DM, Freedman J, Hannon J, Blajchman MA (2005) Proceedings of a consensus conference: towards and understanding of TRALI. Transfus Med Rev 19:2-31

4. Vlaar AP, Binnekade JM, Prins D, Van Stein D, Hofstra JJ, Schultz MJ, Juffermans NP (2010) Risk factors and outcome of transfusion-related acute lung injury in the critically ill: a nested case-control study. Crit Care Med 38:771-778

5. Triulzi D (2009) Transfusion-related acute lung injury: current concepts for the clinician. Anesthe-Analg 108:770-776

6. Propovsky MA, Abel MD, Moore SB (1983) Transfusion-related acute lung injury associated with passive transfer of antileukocyte antibodies. Am Rev Respir Dis 128:185-189

7. Propovsky MA, Chaplin HC, Moore SB (1992) Transfusionrelated acute lung injury: a neglected, serious complication of homotherapy. Transfusion 32:589-592

8. Yomtovian R, Kline W, Press C (1984) Severe pulmonary hypersensitivity associated with passive transfusion of a neutrophil-specific antibody. Lancet 1:244-246

9. Baggiolini M, Walz A, Kunkel SL (1989) Neutrophil-activating peptide-1/interleukin 8 , a novel cytokin that activates neutrophils. J Clin Investig 84:1045-1049

10. Borish L, Rosenbaum R, Albury L, Clark S (1989) Activation of neutrophils by recombinant interleukin 6. Cell Immunol 121: 280-289

11. Sarkodee-Adoo CB, Kendall JM, Sridhara R, Lee EJ, Schiffer CA (1998) The relationship between the duration of platelet storage and the development of transfusion reactions. Transfusion 38: 229-235

12. Webert KE, Blajchman MA (2005) Transfusion-related acute lung injury. Curr Opin Hematol 12:480-487 